\title{
SCIENTIFIC REPORTS

\section{Daily exposure to formaldehyde and acetaldehyde and potential health risk associated with use of high and low nicotine e-liquid concentrations}

\begin{abstract}
Leon Kosmider $\mathbb{1}^{1 *}$, Sharon $\mathrm{Cox}^{2}$, Marzena Zaciera ${ }^{3}$, Jolanta Kurek ${ }^{3}$, Maciej L. Goniewicz $\mathbb{D}^{4}$, Hayden McRobbie ${ }^{5}$, Catherine Kimber ${ }^{2} \&$ Lynne Dawkins ${ }^{2}$

Recent evidence suggests that e-cigarette users tend to change their puffing behaviors when using e-liquids with reduced nicotine concentrations by taking longer and more frequent puffs. Using puffing regimens modelled on puffing topography data from 19 experienced e-cigarette users who switched between 18 and $6 \mathrm{mg} / \mathrm{mL}$ e-liquids with and without power adjustments, differences in daily exposure to carbonyl compounds and estimated changes in cancer risk were assessed by production of aerosols generated using a smoking machine and analyzed using gas and liquid chromatography. Significant differences across conditions were found for formaldehyde and acetaldehyde $(p<0.01)$. Switching from a higher to a lower nicotine concentration was associated with greater exposure regardless of whether power settings were fixed or adjustable which is likely due to increased liquid consumption under lower nicotine concentration settings. Daily exposure for formaldehyde and acetaldehyde was higher for $17 / 19$ participants when using low $(6 \mathrm{mg} / \mathrm{mL})$ compared with high $(18 \mathrm{mg} / \mathrm{mL})$ nicotine e-liquid concentration when power was fixed. When power adjustments were permitted, formaldehyde and acetaldehyde levels were higher respectively for 16/19 and 14/19 participants with the use of 6 compared with $18 \mathrm{mg} / \mathrm{mL}$ nicotine e-liquid.
\end{abstract}

Although the long-term health effects of e-cigarette use remain unknown, published research indicates that e-cigarette aerosol contains far lower levels of toxins and carcinogens compared to tobacco smoke ${ }^{1}$. In a modelling study based on published data from chemical analyses of emissions from e-cigarette aerosols, Stephens concluded that e-cigarette emissions mostly have cancer potencies $<1 \%$ of tobacco smoke, although there were some exceptions ${ }^{2}$. Similarly, biomarker studies have reported a more favorable toxicity profile in e-cigarette users compared with smokers ${ }^{3-7}$.

Nevertheless, a range of factors associated with both device characteristics and user behavior are likely to influence toxicity profile as well as nicotine exposure and quitting potential. Chemical emission studies using bench top tests/smoking machines have explored carbonyl compound emissions using different e-cigarette generations $^{3,8}$, product characteristics ${ }^{3,9,10}$ flavors $^{11-14}$ and e-liquid consumption ${ }^{15}$. These laboratory studies differ significantly in the study design and also levels of carbonyl yields ${ }^{16,17}$, which vary from trace levels to levels higher than in tobacco smoke $e^{12,18}$. Similarly, differences in nicotine levels in aerosol have been reported depending on type of device ${ }^{19-23}$, product characteristics ${ }^{24-26}$, and puffing topography ${ }^{11,24,27}$. Although non-human laboratory emission studies can be informative and cost-effective, the device set-up and puffing regimens used may not

\footnotetext{
${ }^{1}$ Department of General and Inorganic Chemistry, Medical University of Silesia, Katowice FOPS in Sosnowiec, Jagiellonska 4, 41-200, Sosnowiec, Poland. ' Centre for Addictive Behaviours Research, School of Applied Sciences, London South Bank University, SE1 OAA, London, UK. ' Department of Chemical Hazard and Genetic Toxicology, Institute of Occupational Medicine and Environmental Health, 41-200, Sosnowiec, Poland. ${ }^{4}$ Roswell Park Cancer Institute, Department of Health Behavior, Buffalo, NY, 14263, USA. ${ }^{5}$ Queen Mary University of London, Wolfson Institute of Preventive Medicine, Barts and The London School of Medicine and Dentistry, E1 4NS, London, UK. *email: leon.kosmider@gmail.com
} 


\begin{tabular}{|c|c|c|c|c|c|c|c|c|c|c|c|c|c|}
\hline \multirow{3}{*}{$\begin{array}{l}\text { Voltage } \\
\text { Nicotine concentration } \\
(\mathrm{mg} / \mathrm{mL})\end{array}$} & \multicolumn{6}{|c|}{ Fixed (F) } & \multicolumn{6}{|c|}{ Adjustable (A) } & \multirow[b]{3}{*}{ Post hoc sig $(<0.05)$} \\
\hline & \multicolumn{3}{|l|}{6} & \multicolumn{3}{|l|}{18} & \multicolumn{3}{|l|}{6} & \multicolumn{3}{|l|}{18} & \\
\hline & N\% & mean $\pm S D$ & $\begin{array}{l}\text { Median } \\
\text { (Q1-Q3) }\end{array}$ & N\% & mean $\pm S D$ & $\begin{array}{l}\text { Median } \\
\text { (Q1-Q3) }\end{array}$ & $\mathbf{N} \%$ & mean $\pm S D$ & $\begin{array}{l}\text { Median (Q1- } \\
\text { Q3) }\end{array}$ & N\% & mean \pm SD & $\begin{array}{l}\text { Median } \\
\text { (Q1-Q3) }\end{array}$ & \\
\hline aerosol yield [g/day] & 100 & $2.98 \pm 1.96$ & $\begin{array}{l}.26 \\
(1.46-4.22)\end{array}$ & 100 & $1.67 \pm 1.14$ & $\begin{array}{l}1.38 \\
(0.7-3.01)\end{array}$ & 100 & $3.42 \pm 2.35$ & $\begin{array}{l}2.64 \\
(1.71-4.85)\end{array}$ & 100 & $2.00 \pm 1.20$ & $\begin{array}{l}1.77 \\
(1.22-2.57)\end{array}$ & $\begin{array}{l}6 \mathrm{~F}>18 \mathrm{~F} ; 6 \mathrm{~A}>18 \mathrm{~A} \\
6 \mathrm{~F}>6 \mathrm{~A} ; 18 \mathrm{~F}>18 \mathrm{~A}\end{array}$ \\
\hline nicotine [mg/day] & 100 & $13.22 \pm 8.93$ & $\begin{array}{l}10.26 \\
(7.43-16.94)\end{array}$ & 100 & $22.69 \pm 15.16$ & $\begin{array}{l}17.88 \\
(10.23-40.04)\end{array}$ & 100 & $15.23 \pm 10.49$ & $\begin{array}{l}13.53 \\
(8.88-19.37)\end{array}$ & 100 & $27.87 \pm 16.86$ & $\begin{array}{l}23.96 \\
(17.73- \\
37.76)\end{array}$ & $\begin{array}{l}18 \mathrm{~F}>6 \mathrm{~F} ; 18 \mathrm{~A}>6 \mathrm{~A} \\
6 \mathrm{~A}>6 \mathrm{~F} ; 18 \mathrm{~A}>18 \mathrm{~F}\end{array}$ \\
\hline formaldehyde [ $\mu \mathrm{g} / \mathrm{day}]$ & 100 & $141.08 \pm 389.44$ & \begin{tabular}{|l}
26.83 \\
$(11.99-$ \\
$56.11)$ \\
\end{tabular} & 100 & $15.81 \pm 10.68$ & $\begin{array}{l}13.69 \\
(6.95-27.99)\end{array}$ & 100 & $229.54 \pm 451.41$ & $\begin{array}{l}25.63(15.82- \\
70.74)\end{array}$ & 100 & $118.46 \pm 291.51$ & $\begin{array}{l}20.23 \\
(10.1-45.57)\end{array}$ & $\begin{array}{l}6 \mathrm{~F}>18 \mathrm{~F} ; 6 \mathrm{~A}>18 \mathrm{~A} \\
18 \mathrm{~A}>18 \mathrm{~F}\end{array}$ \\
\hline acetaldehyde [ $\mu \mathrm{g} / \mathrm{day}]$ & 100 & $47.89 \pm 74.11$ & $\begin{array}{l}19.91 \\
(4.68-66.47)\end{array}$ & 100 & $19.09 \pm 22.72$ & $\begin{array}{l}8.18 \\
(3.42-34.03)\end{array}$ & 100 & $79.86 \pm 118.23$ & $\begin{array}{l}20.17 \\
(5.61-83.00)\end{array}$ & 100 & $47.86 \pm 74.59$ & $\begin{array}{l}15.54 \\
(4.87-51.26)\end{array}$ & $\begin{array}{l}6 \mathrm{~F}>18 \mathrm{~F} ; 6 \mathrm{~A}>18 \mathrm{~A} \\
18 \mathrm{~A}>18 \mathrm{~F}\end{array}$ \\
\hline $\begin{array}{l}\text { Formaldehyde/g of } \\
\text { aerosol }[\mu \mathrm{g} / \mathrm{g}]\end{array}$ & 100 & $26.87 \pm 54.69$ & $\begin{array}{l}9.31 \\
(7.24-16.15)\end{array}$ & 100 & $9.82 \pm 2.07$ & $\begin{array}{l}10.27 \\
(8.83-11.40\end{array}$ & 100 & $47.71 \pm 89.60$ & $\begin{array}{l}10.58 \\
(8.58-16.26)\end{array}$ & 100 & $40.56 \pm 85.18$ & $\begin{array}{l}11.34 \\
(8.51-20.23)\end{array}$ & $\mathrm{ns}$ \\
\hline $\begin{array}{l}\text { Acetaldehyde/g of } \\
\text { aerosol }[\mu \mathrm{g} / \mathrm{g}]\end{array}$ & 100 & $20.29 \pm 30.36$ & \begin{tabular}{|l|}
5.21 \\
$(2.42-38.69)$
\end{tabular} & 100 & $19.16 \pm 31.31$ & $\begin{array}{l}4.33 \\
(2.59-20.62)\end{array}$ & 100 & $28.13 \pm 39.06$ & $\begin{array}{l}5.15 \\
(2.50-48.54)\end{array}$ & 100 & $25.66 \pm 35.41$ & \begin{tabular}{|l|}
8.78 \\
$(2.95-35.95)$
\end{tabular} & ns \\
\hline
\end{tabular}

Table 1. Daily exposure to aerosol, nicotine, formaldehyde, acetaldehyde and formaldehyde \& acetaldehyde per gram of aerosol yield. Results were analysed using non-parametric Friedman tests on medians with post-hoc Wilcoxon signed rank tests to compare differences between conditions. Q1 and Q3 -first and third quartile

reflect real-world usage patterns. Thus, it has been suggested that e-cigarettes should be tested for safety under realistic conditions ${ }^{28}$ in order to better understand the long-term health effects of product use.

We have previously shown, in a study of e-cigarette users vaping in the laboratory ${ }^{29}$, that reduced nicotine concentration $(6 \mathrm{mg} / \mathrm{mL}$ compared with $24 \mathrm{mg} / \mathrm{mL})$ used within the same device results in compensatory puffing (longer and more frequent puffs), consequently increasing carbonyl mouth exposure to the users ${ }^{30}$. Nevertheless, vaping behavior in the lab, even under ad libitum conditions may not accurately reflect everyday 'real-life' usage, particularly when power can be adjusted as with newer generation devices. In a more recent companion study to the current paper ${ }^{31}$, we characterized e-cigarette use patterns (daily puff number, puff duration and inter-puff interval [IPI]) and changes to power (where permitted) outside the lab, across four conditions (each condition lasting a week): (i) low nicotine/fixed power); (ii) low nicotine/adjustable power; (iii) high nicotine/fixed power); iv) high nicotine/adjustable power (where low $=6 \mathrm{mg} / \mathrm{mL}$ and high $=18 \mathrm{mg} / \mathrm{mL}$ ) Use of the lower nicotine concentration e-liquid was again associated with more intensive puffing patterns (higher number and duration of puffs) especially when power settings could not be adjusted. These studies clearly illustrate that when nicotine is reduced, vapers are likely to engage in compensatory behavior by increasing the power on their devices and/or puffing more intensively. Both power ${ }^{8,15}$ and puffing topography ${ }^{30}$ may affect toxicant emissions, but the extent to which such compensatory behavior affects daily toxicant exposure and subsequent health risk is unknown.

The current study aimed to estimate daily carbonyl exposure, change in cancer risk potency, aerosol yield and nicotine exposure associated with the puffing regimens used in our published human participant study $y^{31}$. We used a smoking machine in the laboratory to mimic vapers' puffing patterns under the different nicotine e-liquid concentration and power conditions used in our previous study ${ }^{31}$. Toxicant yields per puff were then scaled up by the number of puffs taken per day by each participant in each condition to estimate daily toxicant exposure. We also performed a comparison of cancer risk potencies using the puffing regimens associated with use of both the high $(18 \mathrm{mg} / \mathrm{mL})$ and low $(6 \mathrm{mg} / \mathrm{mL})$ nicotine concentration e-liquids to determine whether compensatory behavior increased cancer risk potency. The main compounds of interest were carbonyl compounds (mainly formaldehyde and acetaldehyde), as the main carcinogens in e-cigarette aerosols ${ }^{2}$ and nicotine, because of its addictive potential. We hypothesized that the compensatory puffing patterns associated with using 6 (compared with 18 ) $\mathrm{mg} / \mathrm{mL}$ nicotine e-liquid, particularly under adjustable power settings, would be associated with higher aerosol yield, higher formaldehyde and acetaldehyde emissions, and higher cancer risk potencies.

\section{Results}

Daily aerosol yield and nicotine exposure. Estimated daily aerosol yield and nicotine exposure were both calculated by multiplying the yield per puff by the mean daily number of puffs taken by each participant in each condition.

Table 1 presents the median (IQR) and mean (SD) values for the two nicotine strengths under fixed (F) and adjustable (A) voltage settings for daily aerosol yield and nicotine exposure whilst Figs. 1 and 2 illustrates the number of participants with increased or decreased exposure.

In the $6 \mathrm{mg} / \mathrm{mL}$ nicotine condition, the median g/day e-liquid consumed was higher under adjustable (A) compared with fixed (F) voltage settings. In the $18 \mathrm{mg} / \mathrm{mL}$ nicotine condition, consumption was also higher under $\mathrm{F}$ and $\mathrm{A}$ voltage settings. Friedman analysis showed statistically significant differences between conditions (6F, 18F, 6A, 18A: $\left.\mathrm{p}<0.01, \mathrm{~N}=19, \mathrm{DF}=3, X^{2}=33.4\right)$.

Wilcoxon Signed Ranks Tests revealed a significant difference between $6 \mathrm{mg} / \mathrm{mL}$ and $18 \mathrm{mg} / \mathrm{mL}$ within both $\mathrm{F}$ and A settings. Expressed as frequencies, 19/19 users increased their e-liquid consumption when using 6 compared with $18 \mathrm{mg} / \mathrm{mL}$ nicotine concentration e-liquids when voltage settings were fixed and 15/19 increased their consumption in the 6 vs $18 \mathrm{mg} / \mathrm{mL}$ condition when settings were adjustable ( $6 \mathrm{~F}$ vs $18 \mathrm{~F}$ and $6 \mathrm{~A}$ vs. $18 \mathrm{~A}, \mathrm{p}<0.01)$. 


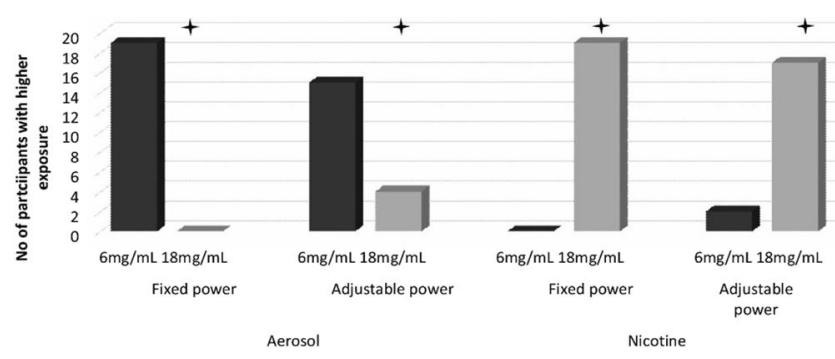

Figure 1. Number of participants with higher daily aerosol and nicotine mouth exposure with $6 \mathrm{vs.} 18 \mathrm{mg} / \mathrm{mL}$ e-liquid under each power condition.

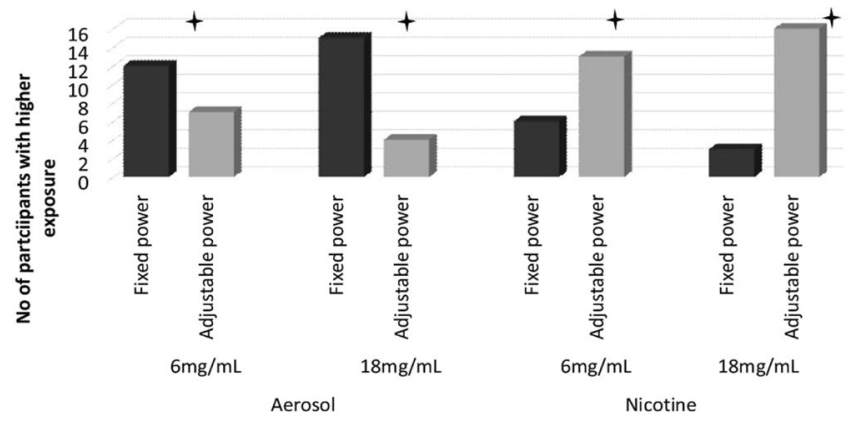

Figure 2. Number of participants with higher daily aerosol and nicotine mouth exposure with fixed vs. adjustable power settings under each e-liquid nicotine strength.

There was also a statistically significant difference in e-liquid consumption between $\mathrm{F}$ and A settings within the same nicotine strength e-liquid (for both 6 and $18 \mathrm{mg} / \mathrm{mL} \mathrm{p}<0.05$ ); 12/19 users had higher daily e-liquid consumption when comparing $6 \mathrm{~F}$ to $6 \mathrm{~A}$ and $15 / 19$ when comparing $18 \mathrm{~F}$ to $18 \mathrm{~A}$.

Similar differences were found for daily nicotine exposure (Friedman test: $\mathrm{p}<0.01, \mathrm{~N}=19, \mathrm{DF}=3$, $X^{2}=41.8$ ). Average values respectively for fixed and adjustable settings are shown in Table 1 .

Wilcoxon Signed Ranks Test revealed a significant difference between $6 \mathrm{mg} / \mathrm{mL}$ and $18 \mathrm{mg} / \mathrm{mL}$ within both the $\mathrm{F}$ and A settings. 17/19 users had higher nicotine mouth exposure when using $18 \mathrm{mg} / \mathrm{mL}$ e-liquid compared to $6 \mathrm{mg} / \mathrm{mL}$ e-liquid under adjustable $(\mathrm{A})$ power settings $(\mathrm{p}<0.01)$. When power settings were fixed $(\mathrm{F})$, all participants had higher daily mouth nicotine exposure in the $18 \mathrm{mg} / \mathrm{mL}$ condition $(\mathrm{p}<0.01)$.

There were also statistically significant differences between $\mathrm{F}$ and A settings within the same nicotine strength e-liquid. 13 and 16/19 participants were exposed to higher daily amount of nicotine inhaled under A compared to F settings for $6(\mathrm{p}=0.04)$ and $18 \mathrm{mg} / \mathrm{mL}(\mathrm{p}=0.01)$ nicotine e-liquids respectively.

Daily exposure to carbonyl compounds with carcinogenic potential. The chromatographic method used in our study allowed us to measure 15 different carbonyl compounds in e-liquids and e-cigarette aerosol. However, the main focus of this paper is to compare health risk to the user, so a statistical analysis was performed only for formaldehyde and acetaldehyde. Estimated daily carbonyl exposure was calculated by multiplying the carbonyl yield per puff by the mean daily number of puffs taken by each participant in each condition. The median (IQR) and means (SD) for the analysed compounds can be found in Table 1 and all other non-analysed compounds quantified are shown in Table 2. Graph(s) depicting the number of participants who increased their formaldehyde and acetaldehyde exposure (as per our Friedman analysis) can be found in Figs. 3 and 4. In the analysis that follows, only median values are presented, as carbonyl yield characteristically adds skewness to the data.

There was a significant difference across conditions in relation to formaldehyde (Friedman Test $\mathrm{p}<0.01$, $\mathrm{N}=19, \mathrm{DF}=3, X^{2}=29.4$ ). The median of daily mouth exposure to formaldehyde for the $6 \mathrm{mg} / \mathrm{mL}$ nicotine e-liquid condition was similar across fixed versus adjustable (A) settings. For the $18 \mathrm{mg} / \mathrm{mL}$ condition, the median was higher under adjustable compared to fixed settings (see Table 1).

In terms of frequencies (shown in Fig. 3), daily mouth exposure for formaldehyde was higher for 17/19 participants under Fixed settings and for 16/19 under Adjustable settings when the $6 \mathrm{mg} / \mathrm{mL}$ nicotine e-liquid was used in comparison with the $18 \mathrm{mg} / \mathrm{mL}$ nicotine e-liquid (both $\mathrm{p}<0.01$ ). When comparing differences for Fixed vs. Adjustable within the same nicotine strength (shown in Fig. 4), 18/19 participants had higher daily mouth exposure under Adjustable vs. Fixed settings when using $18 \mathrm{mg} / \mathrm{mL}(\mathrm{p}<0.01) .12 / 19$ participants had higher daily mouth exposure under Adjustable vs. the Fixed settings when using $6 \mathrm{mg} / \mathrm{mL}$ liquid $(\mathrm{p}>0.05)$.

A similar pattern was observed for acetaldehyde, where median values were similar for $\mathrm{F}$ and A settings for the $6 \mathrm{mg} / \mathrm{mL}$ nicotine e-liquids condition, and lower for $\mathrm{F}$ and A settings for $18 \mathrm{mg}$ nicotine e-liquid (see Table 1). Friedman Test showed significant differences between conditions $\left(\mathrm{p}<0.01, \mathrm{~N}=19, \mathrm{DF}=3, X^{2}=27.8\right)$. 


\begin{tabular}{|c|c|c|c|c|c|c|c|c|c|c|c|c|}
\hline \multirow{3}{*}{$\begin{array}{l}\text { Voltage } \\
\text { Nicotine concentration }(\mathrm{mg} / \mathrm{mL})\end{array}$} & \multicolumn{6}{|c|}{ Fixed } & \multicolumn{6}{|c|}{ Adjustable } \\
\hline & \multicolumn{3}{|l|}{6} & \multicolumn{3}{|l|}{18} & \multicolumn{3}{|l|}{6} & \multicolumn{3}{|l|}{18} \\
\hline & N\% & mean $\pm S D$ & $\begin{array}{l}\text { Median } \\
\text { (Q1-Q3) }\end{array}$ & N\% & mean $\pm S D$ & $\begin{array}{l}\text { Median } \\
\text { (Q1-Q3) }\end{array}$ & N\% & mean $\pm S D$ & $\begin{array}{l}\text { Median } \\
\text { (Q1-Q3) }\end{array}$ & N\% & mean $\pm S D$ & $\begin{array}{l}\text { Median } \\
\text { (Q1-Q3) }\end{array}$ \\
\hline acrolein [ $\mu \mathrm{g} / \mathrm{day}]$ & 72 & $* 103.5 \pm 361.08$ & $\begin{array}{l}5.15(1.06- \\
34.52)\end{array}$ & 56 & $* 6.05 \pm 8.1$ & $\begin{array}{l}1.31(0.68- \\
10.59)\end{array}$ & 84 & $* 101.6 \pm 296.82$ & $\begin{array}{l}15.16 \\
(2.03- \\
53.45)\end{array}$ & 74 & $* 27.31 \pm 52.82$ & $\begin{array}{l}5.1(1.13- \\
25.14)\end{array}$ \\
\hline acetone $[\mu \mathrm{g} / \mathrm{day}]$ & 91 & $* 13.84 \pm 12.59$ & $\begin{array}{l}10.22 \\
(4.04- \\
25.15) \\
\end{array}$ & 100 & $8.94 \pm 7.53$ & $\begin{array}{l}6.21(2.91- \\
18.38)\end{array}$ & 95 & $* 13.01 \pm 11.92$ & $\begin{array}{l}9.09(5.37- \\
17.98)\end{array}$ & 88 & $* 10.75 \pm 10.02$ & $\begin{array}{l}8.49 \\
(3.86-13.71)\end{array}$ \\
\hline propionaldehyde [ $\mu \mathrm{g} / \mathrm{day}]$ & 88 & $* 5.45 \pm 15.01$ & $\begin{array}{l}1.54 \\
(1.02-2.82)\end{array}$ & 70 & $* 1.05 \pm 0.9$ & $\begin{array}{l}0.85 \\
(0.41-1.64)\end{array}$ & 89 & $* 10.19 \pm 20.15$ & $\begin{array}{l}2.21 \\
(1.25-3.64)\end{array}$ & 77 & $* 5.39 \pm 10.45$ & $\begin{array}{l}1.61 \\
(0.43-2.03)\end{array}$ \\
\hline 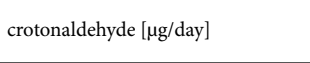 & 12 & $* 1.01 \pm 2.94$ & $\begin{array}{l}0.17 \\
(0-0.52)\end{array}$ & 7 & $* 0.46 \pm 1.52$ & $0(0-0.32)$ & 25 & $* 1.48 \pm 3.84$ & $\begin{array}{l}0.39 \\
(0-0.89)\end{array}$ & 26 & $* 0.62 \pm 1.03$ & $0.21(0-0.64)$ \\
\hline butyraldehyde [ $\mu \mathrm{g} / \mathrm{day}]$ & 44 & $* 0.83 \pm 1.01$ & \begin{tabular}{|l|}
0.33 \\
$(0-1.89)$ \\
\end{tabular} & 53 & $* 0.88 \pm 1.26$ & $\begin{array}{l}0.4 \\
(0.13-1.45)\end{array}$ & 40 & $* 1.25 \pm 2.17$ & $\begin{array}{l}0.39 \\
(0-1.73)\end{array}$ & 47 & $* 0.57 \pm 0.63$ & $\begin{array}{l}0.26 \\
(0.11-1.22)\end{array}$ \\
\hline benzaldehyde [ $\mu \mathrm{g} / \mathrm{day}]$ & 53 & $* 3.84 \pm 6.69$ & $\begin{array}{l}0.49 \\
(0-8.2)\end{array}$ & 47 & $* 1.56 \pm 2.89$ & $\begin{array}{l}0.25 \\
(0-1.27)\end{array}$ & 47 & $* 1.84 \pm 3.1$ & $0.4(0-2.79)$ & 53 & $* 1.43 \pm 2.36$ & $\begin{array}{l}0.37 \\
(0.2-1.15)\end{array}$ \\
\hline isovaleraldehyde $[\mu \mathrm{g} /$ day $]$ & 14 & $* 0.15 \pm 0.34$ & $0(0-0.3)$ & 11 & $* 0.19 \pm 0.55$ & $0(0-0.21)$ & 7 & $* 0.18 \pm 0.6$ & $0(0-0)$ & 2 & $* 0.03 \pm 0.1$ & $0(0-0)$ \\
\hline valeraldehyde [ $\mu \mathrm{g} /$ day] & 81 & $* 11.33 \pm 40.91$ & $\begin{array}{l}0.95 \\
(0.39-3.17)\end{array}$ & 77 & $* 0.88 \pm 0.72$ & $\begin{array}{l}0.58 \\
(0.32-1.31)\end{array}$ & 89 & $* 13.95 \pm 37.32$ & $\begin{array}{l}1.58 \\
(0.51-4.2)\end{array}$ & 86 & $* 3.15 \pm 6.37$ & $\begin{array}{l}1.04 \\
(0.47-2.06)\end{array}$ \\
\hline o-methylbenzaldehyde [ $\mu \mathrm{g} / \mathrm{day}]$ & 89 & $* 10.29 \pm 7.79$ & \begin{tabular}{|l|}
8.24 \\
$(5.3-13.61)$ \\
\end{tabular} & 81 & $* 4.57 \pm 4.28$ & $\begin{array}{l}2.99 \\
(1.56-6.79)\end{array}$ & 95 & $* 8.44 \pm 6.04$ & $\begin{array}{l}8.04(4.38- \\
10.15)\end{array}$ & 93 & $* 4 \pm 1.84$ & $\begin{array}{l}3.57 \\
(2.92-5.11)\end{array}$ \\
\hline m-methylbenzaldehyde [ $\mu \mathrm{g} / \mathrm{day}]$ & 9 & $* 0.55 \pm 1.54$ & $0(0-0)$ & 2 & $* 0.13 \pm 0.4$ & $0(0-0)$ & 25 & $* 1.03 \pm 1.76$ & $0(0-2.37)$ & 11 & $* 0.48 \pm 1.13$ & $0(0-0)$ \\
\hline p-methylbenzaldehyde [ $\mu \mathrm{g} /$ day] & 100 & $45.47 \pm 56.17$ & \begin{tabular}{|l|}
31.19 \\
$(13.73-$ \\
$55.37)$ \\
\end{tabular} & 100 & $16.9 \pm 16.12$ & $\begin{array}{l}10.28 \\
(6.01- \\
27.77)\end{array}$ & 100 & $42.57 \pm 35.07$ & $\begin{array}{l}32.77 \\
(17.3- \\
55.35)\end{array}$ & 100 & $21.08 \pm 13.51$ & $\begin{array}{l}18.52 \\
(9.59-29.46)\end{array}$ \\
\hline hexanal [ $\mu \mathrm{g} /$ day] & 53 & $* 36.87 \pm 104.61$ & \begin{tabular}{|l|}
$0.61(0.38-$ \\
$24.45)$
\end{tabular} & 47 & $* 16.66 \pm 40.36$ & $\begin{array}{l}0.48 \\
(0.36-4.1)\end{array}$ & 37 & $* 24.14 \pm 63.93$ & $\begin{array}{l}0.44 \\
(0-20.05)\end{array}$ & 39 & $* 7.74 \pm 16.32$ & $\begin{array}{l}0.47 \\
(0.2-5.66)\end{array}$ \\
\hline 2,5-dimetylobenzaldehyde [ $\mu \mathrm{g} /$ day] & 5 & $* 0.2 \pm 0.43$ & $0(0-0)$ & 4 & $* 0.17 \pm 0.33$ & $0(0-0)$ & 5 & $* 0.19 \pm 0.42$ & $0(0-0)$ & 0 & $* 0.16 \pm 0.33$ & $0(0-0)$ \\
\hline
\end{tabular}

Table 2. Daily exposure to carbonyl compounds not analysed in the main paper. N\% percentage of samples above limit of quantification in the raw data; *mean value and standard deviation (SD) is only approximation, as artificial values were putted instead of BLQ and ND (see methodology); Q1 and Q3 -first and third quartile.

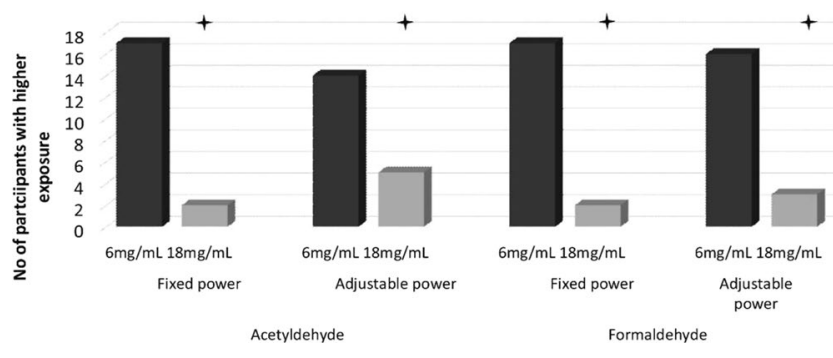

Figure 3. Number of participants with higher daily acetaldehyde and formaldehyde mouth exposure with 6 vs. $18 \mathrm{mg} / \mathrm{mL}$ e-liquid under each power condition.

Wilcoxon Signed Rank Test revealed differences in acetaldehyde daily mouth exposure between $6 \mathrm{~F}$ and $18 \mathrm{~F}$ and $6 \mathrm{~A}$ and 18A. 17/19 participants had higher values in the $6 \mathrm{vs.} 18 \mathrm{mg} / \mathrm{mL}$ nicotine e-liquid condition when settings were fixed $(\mathrm{p}<0.01)$ and $14 / 19$ had higher values in the $6 \mathrm{vs} 18 \mathrm{mg} / \mathrm{mL}$ nicotine e-liquid condition when settings were adjustable ( $\mathrm{p}<0.05$; see Fig. 3). Comparisons between fixed versus adjustable settings showed that, for $18 \mathrm{mg} / \mathrm{mL}$ nicotine use, all participants had higher daily mouth exposure to acetaldehyde under Adjustable vs Fixed $(\mathrm{p}<0.01)$. In the $6 \mathrm{mg} / \mathrm{mL}$ condition, $13 / 19$ participants had higher daily mouth exposure when settings were Adjustable vs Fixed, this difference did not reach statistical significant ( $p>0.05$ ) (See Fig. 4)

To test for differences in daily carbonyls exposure derived by liquid consumption, carbonyl exposure per gram of aerosol yield was calculated and Friedman tests performed. The results for both formaldehyde/g and acetaldehyde/g of aerosol vaporized, Friedman tests were $\mathrm{p}=0.15$ and $\mathrm{p}=0.19$. These values are presented in the Table 1 .

Estimation of cancer risk associated with compensatory behaviors. Our simulation suggests that the Cancer Risk Index (CRI) for formaldehyde [median $\left(1^{\text {st }}\right.$ quartile $-3^{\text {rd }}$ quartile $\left.)\right]$ was $8.1 \times 10^{-6}\left(3.6 \times 10^{-6}\right.$ $\left.-1.7 \times 10^{-5}\right)$ when participants used a low nicotine concentration $(6 \mathrm{mg} / \mathrm{mL})$ without adjusting power $(6 \mathrm{~F})$ and $4.1 \times 10^{-6}\left(2.1 \times 10^{-6}-8.4 \times 10^{-6}\right)$ in the comparable power condition when using the higher nicotine concentration $(18 \mathrm{~F})$. This represents a potential 1.98 fold increase in cancer risk associated with inhaling higher doses of formaldehyde with $6 \mathrm{mg} / \mathrm{mL}$ compared with $18 \mathrm{mg} / \mathrm{mL}$ e-liquid use. When power was adjustable, the CRI for $6 \mathrm{mg} / \mathrm{mL}$ nicotine concentration e-liquid $(6 \mathrm{~A})$ was $7.7 \times 10^{-6}\left(4.8 \times 10^{-6}-2.1 \times 10^{-5}\right)$ and for $18 \mathrm{mg} / \mathrm{mL}$ 


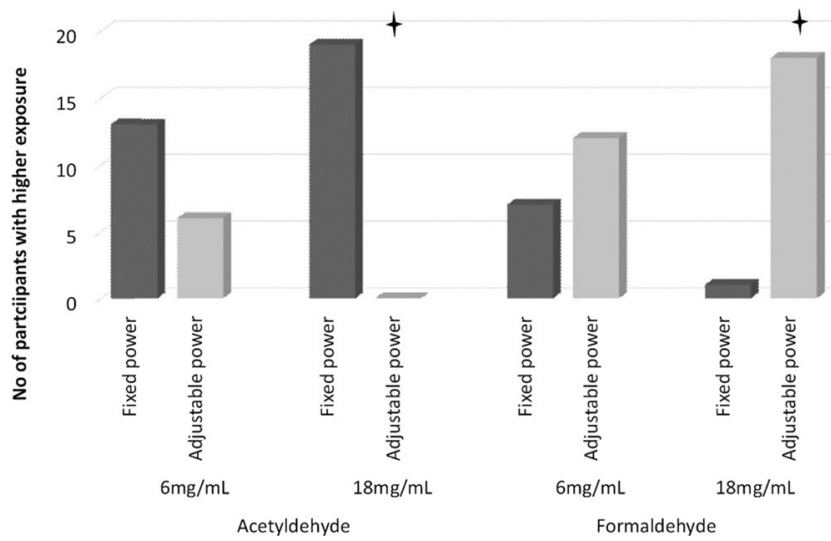

Figure 4. Number of participants with higher daily acetaldehyde and formaldehyde mouth exposure with fixed vs. adjustable power settings under each e-liquid nicotine strength.

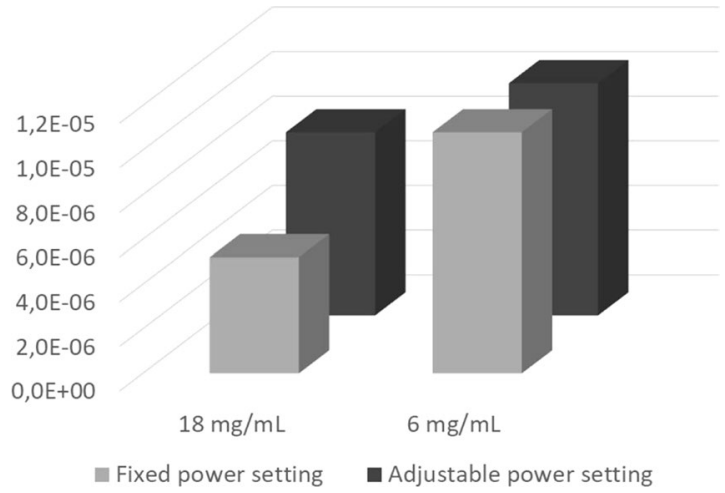

Figure 5. CRI comparison between different experiments settings.

nicotine concentration e-liquid $(18 \mathrm{~A})$, it was $6.1 \times 10^{-6}\left(3.0 \times 10^{-6}-1.4 \times 10^{-5}\right)$ with a 1.26 fold increase for 6 compared with $18 \mathrm{mg} / \mathrm{mL}$ e-liquid nicotine use.

For acetaldehyde [median $\left(1^{\text {st }}\right.$ quartile $-3^{\text {rd }}$ quartile $\left.)\right]$, when using low nicotine concentrations without adjusting power $(6 \mathrm{~F})$ the $\mathrm{CRI}$ was $2.7 \times 10^{-6}\left(6.3 \times 10^{-7}-9.0 \times 10^{-6}\right)$. For $18 \mathrm{~F}$ it was $1.1 \times 10^{-6}\left(4.6 \times 10^{-7}-4.6 \times\right.$ $10^{-6}$ ) representing a potential 2.45 fold increase in cancer risk associated with acetaldehyde with the use of 6 vs. $18 \mathrm{mg} / \mathrm{mL}$ e-liquid. When users could adjust power, the CRI for low nicotine $(6 \mathrm{~A})$ was $2.7 \times 10^{-6}\left(7.6 \times 10^{-7}-\right.$ $\left.1.1 \times 10^{-5}\right)$; and $2.1 \times 10^{-6}\left(6.6 \times 10^{-7}-6.9 \times 10^{-6}\right)$ for high nicotine $(18 \mathrm{~A})$ representing a 1.3 fold increase for 6 compared with $18 \mathrm{mg} / \mathrm{mL}$ e-liquid nicotine use.

When combining cancer potency risk from formaldehyde and acetaldehyde, our simulation suggests a 2.06 fold increase in cancer risk with fixed voltage (F) and a 1.27 fold increase with adjustable voltage (A) when switching from $18 \mathrm{mg} / \mathrm{mL}$ to $6 \mathrm{mg} / \mathrm{mL}$ e-liquids (see Fig. 5)

\section{Discussion}

This study estimated exposure to carbonyl compounds from e-cigarette aerosol based on real-life topography data gathered over one week in a linked study previously published ${ }^{31}$. Here we used the same e-liquids and devices as Dawkins et al. and the mean puffing topography data from each participant under each experimental setting as used by participants. The main aim of this study was to assess any influence of changing usage patterns (compensatory puffing) of the same device under different nicotine concentration and voltage settings on daily exposure to carbonyls and cancer risk potencies. We also estimated the daily aerosol yield and nicotine exposure associated with the usage patterns under each condition.

Using the participant puffing patterns associated with use of the lower $(6 \mathrm{mg} / \mathrm{mL})$ nicotine concentration e-liquid from our previous study ${ }^{31}$, here we demonstrate that significantly more participants increased their daily aerosol yield exposure, formaldehyde exposure and acetaldehyde exposure in both the fixed (F) and adjustable (A) voltage settings. After applying methods used by Stephens ${ }^{2}$ to compare cancer potencies of e-cigarette aerosol, we found that depending on experimental settings, cancer potency factor can increase two to two and half times for users switching from 18 to $6 \mathrm{mg} / \mathrm{mL}$ nicotine e-liquids. It is important to note however, that these values are still lower than tobacco smoke for those compounds, as reported previously ${ }^{2,32}$.

In fact, CRI values $\left(1.1 \times 10^{-6}-7.7 \times 10^{-6}\right)$ reported here approximate the results obtained by Stephens ${ }^{2}$ for e-cigarettes $\left(9.5 \times 10^{-5}\right)$ and medical inhalers $\left(8.9 \times 10^{-6}\right)$; and, the differences can be explained by different 
puffing behaviors and devices used in Stephens' dataset and by the fact, that our team concentrated on carbonyl exposure only. When those values are compared to the CRI calculated by Stephens for tobacco cigarettes $(2.4 \times$ $10^{-2}$ ), the ratio to cigarettes smoked CRI (15 cigarettes per day) to our results was found to be 3116.9 to 21818.2 times higher. In other words, these findings suggest tobacco smoking has a carcinogenic potential of magnitude 3116.9 to 21818.2 times greater than e-cigarette use. Thus, our values represent only $95 \%$ of the total CRI as mentioned by Stephens ${ }^{2}$.

While there are some suggestions for an association between exposure to formaldehyde and increased incidence of lung and nasopharyngeal cancer, it is worth noting that the CRI methodology assumes that cancer risk is linear in the whole range of exposure. In fact, studies suggesting such associations may be limited due to possible exposure to other agents that may have contributed to causing cancers ${ }^{33}$. On the other hand, animal models reveal that cancer potential of formaldehyde might be not linear, especially in low concentrations. As showed by Monticello et al. ${ }^{34}$ concentration of formaldehyde of $2 \mathrm{ppm}(2.4 \mathrm{mg} / \mathrm{m} 3)$ for $6 \mathrm{~h}$ a day for 5 days per week up to 24 months do not cause cancer in rats. Sharp increases in tumor incidence in the nasal cavity occurred only at concentrations greater than $6 \mathrm{ppm}(7.2 \mathrm{mg} / \mathrm{m} 3)$ formaldehyde. Those results are supported by newer analyses ${ }^{35}$. To compare those values to the values we found in our studies, conservative assumptions (respiratory minute volume-40L; assuming that participants where using e-cigarette for $16 \mathrm{~h} /$ day) were taken. Hypothetical exposure concentrations between the lowest $Q_{1}$ and the highest $Q_{3}$ values taken $(6.95 \mu \mathrm{g} /$ day for $18 \mathrm{mg} F$ setting and $70.74 \mu \mathrm{g} /$ day for $6 \mathrm{mg}$ A setting), were within range from $0.0015 \mathrm{ppm}(0.0018 \mathrm{mg} / \mathrm{m} 3)$ to.015 ppm $(0.018 \mathrm{mg} /$ $\mathrm{m} 3)$. These are much lower than the values which were proven to cause cancer in animal models (6 ppm). Similar analyses for acetaldehyde are difficult due to the lack of sufficient animal models assessing the carcinogenicity of low concentrations acetaldehyde by inhalation.

These findings are consistent with our previous work which, through the use of two different methods (analysis of aerosol generated in the lab and exposure to biomarkers of exposure in human urine), has indicated higher formaldehyde exposure when lower nicotine e-liquids are used ${ }^{31}$. Here, most participants showed an increase in daily exposure to all carcinogenic or potentially carcinogenic carbonyl compounds when the device was used with the lower nicotine concentration e-liquid. Our results suggest that aerosol yield and liquid consumption per day were the main determinants of the differences in daily formaldehyde and acetaldehyde exposure between conditions. This finding is in agreement with studies reporting that while aldehydes levels per puff are dependent on power settings, aldehydes levels per gram liquid consumption are independent of power settings when the devices are used in realistic conditions ${ }^{15,18}$. Still, a limitation of this particularly analysis is that there may not be enough statistical power to detect differences between conditions in aldehyde exposure per g of liquid consumption. Nevertheless, increasing nicotine delivery while keeping carbonyl emissions low should potentially reduce any health risk from vaping. This was demonstrated recently in a study of JUUL ${ }^{36}$ which delivers high nicotine but operates at low power by limiting its peak temperature. Nicotine-normalized formaldehyde and total carbonyl yields were lower respectively by six fold and 50 fold compared to combustible cigarettes and lower than other previously studied e-cigarettes.

However, analysis of carbonyl compounds in the liquid, did reveal some differences in formaldehyde and acetaldehyde content between different bottles of the same batch which reached up to $30 \%$. Interestingly, the amount of those two compounds differed between the $6 \mathrm{mg} / \mathrm{mL}$ and $18 \mathrm{mg} / \mathrm{mL}$ nicotine concentration e-liquids used in the study (within the same brand of e-liquid), usually, although not consistently, higher amounts were found in the $6 \mathrm{mg} / \mathrm{mL}$ liquids. Although this might have had an influence on carbonyls yield, it should not influence the general trend, as the daily exposure to formaldehyde and acetaldehyde exceeded the yield of those compounds which would be found in the amount of e-liquids vaporized daily. This suggests that most of the formaldehyde and acetaldehyde exposure is a result of degradation of e-liquid components. Previous reports suggest that formaldehyde and acetaldehyde in aerosol might be related to the power of the device and the composition of the e-liquid $3,16,27,37-39$.

Some of the results were below the limit of detection and artificial value was used in those cases. This however, should not influence our results as non-parametric analyses was performed. In our analysis of cancer risk, only carbonyls were considered, as we did not quantify other carcinogenic compounds, so the results of relative cancer risk potential might be underestimated. However, according to Stephens, carbonyl compounds are responsible for more than $95 \%$ of cancer potency of e-cigarette aerosol ${ }^{2}$.

We also checked whether the actual nicotine content of the liquid corresponded to the labels on the bottles. In each case, we analyzed three bottles from the batch used in the study and nicotine content in the liquid differ substantially from bottle labels. For 11 of 14 samples (79\%), the actual nicotine content was within $10 \%$ of the value on the labels. These results are largely consistent with the literature with the exception of a few previous reports ${ }^{40-44}$. Three samples, which did not meet targeted concentrations, had lower than declared nicotine levels; this may be explained by the degradation of the product over time. The variation between different bottles of the same e-liquid did not exceed $10 \%$ (relative standard deviation). Thus, we concluded, that the quality of e-liquids used in this study do not differ significantly from average e-liquids available on the market ${ }^{44-46}$.

This study is also the first attempt to describe daily mouth exposure to nicotine, aerosol yield and carbonyl compounds, based on puffing patterns and emissions from an e-cigarette. Daily nicotine exposure depended on nicotine concentration used and whether voltage was fixed or adjustable. Although using a lower nicotine level e-liquid, especially under fixed voltage conditions, was related to lower nicotine exposure in comparison with higher nicotine e-liquid, the results of our daily aerosol exposure suggest that e-cigarettes were used more intensively with lower nicotine concentration e-liquids, supporting our previous findings ${ }^{29,30}$. These results suggest that compensatory behaviors such as number of puffs, puff duration and device power are insufficient to inhale equal amount of nicotine after switching from $18 \mathrm{mg} / \mathrm{mL}$ to $6 \mathrm{mg} / \mathrm{mL}$ using the same device. Thus, our findings suggest switching to lower nicotine concentrations might increase liquid consumption (through compensatory puffing) 
result in higher carbonyl exposure, and a decrease in nicotine exposure. Thus, a regulatory framework which restrict nicotine concentrations may have the unintended consequences of increasing toxin exposure to users.

In conclusion, using puffing topography and device setting data from a real-world sample of e-cigarette users, use of a lower $(6 \mathrm{mg} / \mathrm{mL})$ nicotine concentration e-liquid was associated with higher formaldehyde and acetaldehyde exposure regardless of whether voltage settings were fixed or adjustable, resulting in an estimated 2 fold increase in cancer risk. Our results also suggest that the compensatory behavior is not sufficient to compensate nicotine mouth-exposure. A combination of effective nicotine delivery (to reduce compensatory puffing) and low carbonyl emissions may reduce potential health risk from vaping. As changing puffing behaviors might be unconscious, vapers should exercise caution when transitioning to lower nicotine concentrations.

\section{Methods}

Human puffing topography data. Nineteen participants took part in the study as previously described $^{31,47}$. Ethical approval (including all experimental protocols) was granted by London South Bank University (Application reference: UREC 1604) and has been funded by Cancer Research UK (Application reference: C50878/A21130). Informed consent was collected in writing at the baseline session at the University prior to any data collection. A statement to confirm that all methods were carried out in accordance with relevant guidelines and regulations. All methods were carried out in accordance with relevant guidelines and regulations

Participants used an eVic Supreme ${ }^{\mathrm{TM}}$ by Joytech fitted with a 'Nautilus Aspire' $5 \mathrm{~mL}$ tank housing a BVC atomizer $(1.6 \mathrm{ohm})$ for at least one week in each of four counterbalanced conditions. Conditions included, $6 \mathrm{mg} / \mathrm{mL}$ nicotine with a fixed $4.0 \mathrm{~V}$ battery output voltage (6 Fixed $[6 \mathrm{~F}]) ; 18 \mathrm{mg} / \mathrm{mL}$ nicotine with a fixed $4.0 \mathrm{~V}$ battery output voltage (18 Fixed [18F]); $6 \mathrm{mg} / \mathrm{mL}$ nicotine with adjustable (as desired by the user) output voltage (6 Adjustable [6 A]); and $18 \mathrm{mg} / \mathrm{mL}$ nicotine with adjustable output voltage (18 Adjustable [18 A]). Participants had a choice of four e-liquid (though participants were obliged to use the same flavor through the whole experiment). The e-cigarette recorded details of each puff parameter, including time, puff duration (PD) and battery output voltage (BOV) for 6 and 18 adjustable (A) settings throughout the 4 weeks. Inter-puff intervals (IPI) were calculated by subtraction between duration of the puff by the time of the previous puff. Puff duration and battery output voltage were characterized with a normal distribution, so for each participant in each condition $(6 \mathrm{~F}, 18 \mathrm{~F}$, $6 \mathrm{~A}, 18 \mathrm{~A}$ ) mean values were calculated. As the inter-puff interval raw data where highly skewed, the median value was calculated, as the most reasonable description of the central tendency of IPI (See Dawkins et. al. ${ }^{31}$ ). Due to device error, puffing topography data was collected for 19/20 participants.

E-liquids. Participants chose from 4 different e-liquid flavors (tobacco, fruit, bakery and menthol), and were required to use the same e-liquid for the duration of the study (in both 6 and $18 \mathrm{mg} / \mathrm{mL}$ nicotine conditions). The same e-liquid used by each participant was used in the laboratory to mimic puffing behaviors. In total, 7 e-liquids ( 3 fruit flavors, 2 menthol flavors, one tobacco and one sweet/bakery) were chosen from two different manufacturers. E-liquids were analyzed for nicotine and carbonyl compound using the methods described below. For analysis, $50 \mu \mathrm{L}$ of e-liquid was added to sorbent removed from sorbent tubes (carbonyl compounds) and stored in the refrigerator for $24 \mathrm{~h}$, or diluted in $10 \mathrm{~mL}$ of methanol (nicotine). To measure density of e-liquids, $50 \mu \mathrm{L}$ of e-liquid was weighted and density was calculated dividing the mass/volume. Three bottles of each e-liquid were tested each time.

Density of e-liquids varied from 1.14 to $1.17 \mathrm{~g} / \mathrm{mL}$ with a mean of $1.16 \pm 0.01 \mathrm{~g} / \mathrm{mL}$. Results of the nicotine and carbonyl content analysis are presented in Supplementary Table 1. Mean concentration of nicotine was $5.59 \pm 0.75$ and $18.03 \pm 1.24$ respectively for $6 \mathrm{mg} / \mathrm{mL}$ and $18 \mathrm{mg} / \mathrm{mL}$ e-liquids. The highest difference between label and actual content was $30 \%$ (e-liquid e: $6 \mathrm{mg} / \mathrm{mL}$, fruit flavor).

Formaldehyde was detected in $6 / 7$ e-liquids (in both the $6 \mathrm{mg} / \mathrm{mL}$ and $18 \mathrm{mg} / \mathrm{mL}$ nicotine concentrations), with concentrations varying from $1.11 \pm 0.10$ (e-liquid b: menthol flavor) to $4.66 \pm 0.67 \mu \mathrm{g} / \mathrm{mL}$ (e-liquid g: blueberry muffin flavor). The mean value of formaldehyde was $2.0 \pm 1 \mu \mathrm{g} / \mathrm{mL}(2.40 \pm 1.24$ and $1.58 \pm 0.38$ for 6 and $18 \mathrm{mg} / \mathrm{mL}$ e-liquids respectively). The highest concentration of formaldehyde was found in the bakery flavor (g) $6 \mathrm{mg} / \mathrm{mL}$ e-liquid: $4.66 \pm 0.67 \mathrm{vs} 1.85 \pm 0.11 \mu \mathrm{g} / \mathrm{mL}$ for $18 \mathrm{mg} / \mathrm{mL}(\mathrm{p}<0.05)$. Two out of three fruit flavors also had significantly higher levels of formaldehyde in the $6 \mathrm{mg} / \mathrm{mL}$ vs the $18 \mathrm{mg} / \mathrm{mL}$ nicotine concentrations $(2.79 \pm 0.26$ vs $1.22 \pm 0.12$, and $2.59 \pm 0.08$ vs $1.51 \pm 0.17 \mu \mathrm{g} / \mathrm{mL}$ for $6 \mathrm{vs} 18 \mathrm{mg} / \mathrm{mL}$ nicotine concentrations respectively.

Acetaldehyde was detected in all e-liquids in concentrations varying from $0.84 \pm 0.01(18 \mathrm{mg} / \mathrm{mL}$ e-liquid b: menthol flavor) to $293.18 \pm 13.68 \mu \mathrm{g} / \mathrm{mL}$ ( $6 \mathrm{mg} / \mathrm{mL}$ e-liquid g: bakery flavor). The mean concentration for acetaldehyde was $54.89 \pm 96.24 \mu \mathrm{g} / \mathrm{mL}(55.64 \pm 103.87$ and $54.15 \pm 90.55$ for 6 and $18 \mathrm{mg} / \mathrm{mL}$ e-liquids respectively). One brand (e-liquid c: menthol flavor) had statistically lower concentration of acetaldehyde in 6 compared with $18 \mathrm{mg} / \mathrm{mL}$ e-liquid $(0.95 \pm 0.02 \mathrm{vs} 34.97 \pm 1.13 \mu \mathrm{g} / \mathrm{mL})$ and one had higher in 6 compared with $18 \mathrm{mg} / \mathrm{mL}$ (e-liquid g: 'Captain's curse' blueberry muffin flavor): $293.18 \pm 13.68$ vs $260.76 \pm 4.42 \mu \mathrm{g} / \mathrm{mL}$ ).

E-cigarette preparation and aerosol generation. The same e-cigarette and tank model (described above) used by participants in the Dawkins et al. ${ }^{31}$ study was used to mimic puffing patterns in the laboratory. Separate tanks were used for each e-liquid strength and brand. The device was set up with the widest air-flow and the mean battery output voltage used by each participant during each condition. Tanks were filled with $4 \mathrm{~mL}$ of e-liquid ( $80 \%$ of capacity) one day before the experiment. Tanks were rolled for one minute to ensure the wick was soaked and to distribute e-liquid uniformly in the tanks in the time of experiment. Tanks were stored in the dark between experiments. E-cigarettes were charged the day before the experiment and swapped after 15 puffs (one series of aerosol generation) if the level of battery capacity dropped below $50 \%$.

Aerosol from e-cigarettes were generated using the automatic smoking machine Palaczbot (University of Technology, Lodz, Poland) as described previously ${ }^{22,30}$. In the current study we used PD, IPI and BOV obtained 
for each participant recorded by their device through the four-week period in each condition with the e-liquid and device used to test for nicotine, aerosol yield and carbonyls in laboratory condition. Puff volume was fixed to $70 \mathrm{~mL}$.

Amount of vaporized e-liquid was measured by subtracting the mass of the tank after aerosol generation from the mass of the tank before aerosol generation for nicotine analysis as describing previously ${ }^{23}$.

Aerosol yield was generated 3 times for each analysis (for nicotine or carbonyl compounds) to replicate each participant's puffing patterns. Aerosol was tested for carbonyl compounds (i.e. formaldehyde, acetaldehyde, acrolein, benzaldehyde) and nicotine emission with puffing regimes.

Chemical analysis. The method of aldehydes and ketones determination involves an adsorption of aldehydes and ketones aerosol mixture on a pipe filled with silica gel saturated with 2,4-dinitrophenylhydrazine, desorption of the compounds with acetonitrile in an ultrasound washer, and determination using reversed phase high performance liquid chromatography on an AT 1200 liquid chromatograph (Agilent Technologies) equipped with a Zorbax Eclipse PAH column $(4,6 \times 250 \mathrm{~mm}, 5 \mu \mathrm{m})$ and spectrophotometric detector DAD with detection at $360 \mathrm{~nm}$. This allows determination of the following compounds: formaldehyde, acetaldehyde, acrolein, acetone, propionic aldehyde, crotonaldehyde, butanal, benzaldehyde, isovaleric aldehyde, valeric aldehyde, m-methylbenzaldehyde, o-methylbenzaldehyde, p-methylbenzaldehyde, hexanal, 2,5-dimethylbenzaldehyde ${ }^{3,23}$. Limits of detection per sample (50 $\mu \mathrm{L}$ of e-liquid) and per puff are presented in Supplementary Table 2.

Nicotine captured on Cambridge filter was desorbed using $10 \mathrm{~mL}$ of methanol with quinoline as an internal standard, and was analysed using gas chromatography with Thermionic Specific Detector (GC-TSD, Varian Inc. $)^{21,22,47}$.

Statistical analysis. Daily exposure was calculated by multiplying the aerosol, nicotine or carbonyl yield per puff by the mean daily number of puffs taken by each participant in each condition.

Nicotine and carbonyl levels in e-liquids were analyzed using repeated measures analysis of variance (ANOVA). In cases where levels were non quantifiable (ND, BLQ), the median is presented in the results table.

For daily exposure analysis, due to the highly skewed carbonyl data, medians for each replication for each participant under each condition $(6 \mathrm{~F}, 18 \mathrm{~F}, 6 \mathrm{~A}, 18 \mathrm{~A})$ are presented. Nicotine and aerosol daily exposure was normally distributed but for sake of consistency, we report medians and nonparametric analysis throughout although means and SDs are also presented for all variables in Table 1 for sake of completeness.

In cases where a compound was not detected, 0 was used for statistical analysis. When data were below level of detection, the most conservative approach was adopted by taking the middle value of the range between the limit of quantification and detection for analysis (LD + (LQ-LD)/2).

Non-parametric statistical tests for repeated measures ordinal data (Friedman test) were conducted to compare the four condition (6F, 18F, 6A, 18A) (3 degrees of freedom) to detect whether the number of people for whom an increase or decrease was shown between conditions was statistically significant for aerosol yield, nicotine, formaldehyde and acetaldehyde (as potential carcinogens). Where significant, post-hoc Wilcoxon signed-rank tests (two-sided) for repeated measurements was conducted (for $6 \mathrm{~F}$ vs. $6 \mathrm{~A}$; $18 \mathrm{~F}$ vs. $18 \mathrm{~A}$; $6 \mathrm{~F}$ vs. $18 \mathrm{~F}$ and $6 \mathrm{~A}$ vs. $18 \mathrm{~A}$ ). The accepted alpha level was 0.05 .

Statistical analysis was performed using Statistica and IBM SPSS. Raw data including basic statistics (means, medians and checking for normal distribution) were analyzed using Statistica 13.3 (TIBCO Software Inc.). The same software was used to analyze levels of nicotine and carbonyls in e-liquids. The remaining analysis was performed using IBM SPSS Statistics $24^{\text {th }}$ release (IBM Corp.).

Changes in cancer risk potencies. The inhalation unit risk (U) for carcinogen is defined as the excess lifetime cancer risk from continuous inhalation exposure to $1 \mu \mathrm{g}$ of the carcinogen per $\mathrm{m} 3{ }^{48}$ Thus, the cancer risk indices (CRI) for each compound might be calculated by dividing daily exposure in $\mu \mathrm{g} /$ day by the default breathing rate of $20 \mathrm{~m} 3 /$ day and multiplying by unit risk $\left(\mu \mathrm{g} / \mathrm{m}^{3}\right)^{-1} 49$. Although in our study only 2 carcinogens were quantified (formaldehyde - IARC 1 type and acetaldehyde - IARC $2 b$ type), they represent more than $95 \%$ of cancer potency in e-cigarette aerosol according to Stephens ${ }^{2}$. The Office of Environmental Health Hazard Assessment unit risk values were used as previously ${ }^{2}$. $U$, according to this database, is $6.0 \times 10^{-06}$ and $2.7 \times 10^{-06}$ for formaldehyde and acetaldehyde respectively. To compare cancer potency from using e-cigarettes with different settings we calculated change factors by dividing the sum of cancer risk indices from the $18 \mathrm{mg} / \mathrm{mL}$ nicotine e-liquid use by $6 \mathrm{mg} / \mathrm{mL}$ nicotine use in both $\mathrm{F}$ and A settings for median values. Calculated CRIs were not compared statistically, as they are calculated from already analyzed data by multiplying/dividing results by constant values.

Received: 14 June 2019; Accepted: 25 March 2020;

Published online: 16 April 2020

\section{References}

1. Mcneill, A., Brose, L. S., Calder, R., Bauld, L. \& Robson, D. Evidence review of e-cigarettes and heated tobacco products 2018 A report commissioned by Public Health England, https://assets.publishing.service.gov.uk/government/uploads/system/uploads/attachment_ data/file/684963/Evidence_review_of_e-cigarettes_and_heated_tobacco_products_2018.pdf (2018).

2. Stephens, W. E. Comparing the cancer potencies of emissions from vapourised nicotine products including e-cigarettes with those of tobacco smoke. Tob. Control, https://doi.org/10.1136/tobaccocontrol-2017-053808 (2017).

3. Kosmider, L. et al. Carbonyl compounds in electronic cigarette vapors: Effects of nicotine solvent and battery output voltage. Nicotine Tob. Res. 16, 1319-26 (2014).

4. Goniewicz, M. L. et al. Exposure to Nicotine and Selected Toxicants in Cigarette Smokers Who Switched to Electronic Cigarettes: A Longitudinal Within-Subjects Observational Study. Nicotine Tob. Res. 19, 160-167 (2017). 
5. Hecht, S. S. et al. Evaluation of Toxicant and Carcinogen Metabolites in the Urine of E-Cigarette Users Versus Cigarette Smokers. Nicotine Tob. Res. 17, 704-709 (2015).

6. McRobbie, H. et al. Effects of Switching to Electronic Cigarettes with and without Concurrent Smoking on Exposure to Nicotine, Carbon Monoxide, and Acrolein. Cancer Prev. Res. 8, 873-878 (2015).

7. Shahab, L. et al. Nicotine, Carcinogen, and Toxin Exposure in Long-Term E-Cigarette and Nicotine Replacement Therapy Users. Ann. Intern. Med. 166, 390-400 (2017).

8. Talih, S. et al. Juice Monsters: Sub-Ohm Vaping and Toxic Volatile Aldehyde Emissions. Chem. Res. Toxicol. 30, 1791-1793 (2017).

9. EL-Hellani, A. et al. Nicotine and Carbonyl Emissions From Popular Electronic Cigarette Products: Correlation to Liquid Composition and Design Characteristics. Nicotine Tob. Res. 20, 215-223 (2016).

10. Farsalinos, K. E., Voudris, V. \& Poulas, K. E-cigarettes generate high levels of aldehydes only in 'dry puff' conditions. Addiction 110, 1352-1356 (2015).

11. Baassiri, M. et al. Clouds and "throat hit": Effects of liquid composition on nicotine emissions and physical characteristics of electronic cigarette aerosols. Aerosol Sci. Technol. 1-9, https://doi.org/10.1080/02786826.2017.1341040(2017).

12. Khlystov, A. \& Samburova, V. Flavoring Compounds Dominate Toxic Aldehyde Production during E-Cigarette Vaping. Environ. Sci. Technol. 50, 13080-13085 (2016).

13. Kosmider, L. et al. Cherry-flavoured electronic cigarettes expose users to the inhalation irritant, Benzaldehyde. Thorax 71, 376-377 (2016).

14. Pankow, J. F. et al. Benzene formation in electronic cigarettes. Plos One 12, e0173055, https://doi.org/10.1371/journal.pone.0173055 (2017).

15. Farsalinos, K. E. \& Gillman, G. Carbonyl Emissions in E-cigarette Aerosol: A Systematic Review and Methodological Considerations. Front. Physiol. 8, 1119, https://doi.org/10.3389/fphys.2017.01119 (2017).

16. Farsalinos, K., Voudris, V. \& Poulas, K. Response to Shihadeh et al. (2015): E-cigarettes generate high levels of aldehydes only in 'dry puff' conditions. Addiction 110, 1862-1864 (2015).

17. Shihadeh, A., Talih, S. \& Eissenberg, T. Commentary on Farsalinos et al. (2015): E-cigarettes generate high levels of aldehydes only in 'dry puff' conditions. Addiction 110, 1861-1862 (2015).

18. Farsalinos, K. E. et al. Aldehyde levels in e-cigarette aerosol: Findings from a replication study and from use of a new-generation device. Food Chem. Toxicol. 111, 64-70 (2018).

19. Laugesen, M. Nicotine and toxicant yield ratings of electronic cigarette brands in New Zealand. NZMJ 27, 1175-8716 (2015).

20. Prévôt, N. et al. Nicotine delivery from the refill liquid to the aerosol via high-power e-cigarette device. Sci. Rep. 7, 2592 (2017).

21. Goniewicz, M. L., Kuma, T., Gawron, M., Knysak, J. \& Kosmider, L. Nicotine levels in electronic cigarettes. Nicotine Tob. Res. 15, 158-66 (2013).

22. Kosmider, L. et al. Assessment of nicotine concentration in electronic nicotine delivery system (ENDS) liquids and precision of dosing to aerosol. Przegla d Lek. 72, 500-504 (2015).

23. Kośmider, L., Madej, D., Gawron, M. \& Sobczak, A. Influence of electronic cigarettes puffing regimes on amount of vaporized liquid*. Przegl. Lek. 73, 699-703 (2016).

24. Talih, S. et al. Effects of user puff topography, device voltage, and liquid nicotine concentration on electronic cigarette nicotine yield: measurements and model predictions. Nicotine Tob. Res. 17, 150-157 (2015).

25. Kosmider, L., Spindle, T. R., Gawron, M., Sobczak, A. \& Goniewicz, M. L. Nicotine emissions from electronic cigarettes: Individual and interactive effects of propylene glycol to vegetable glycerin composition and device power output. Food Chem. Toxicol. 115, 302-305 (2018).

26. Talih, S. et al. Transport phenomena governing nicotine emissions from electronic cigarettes: model formulation and experimental investigation. Aerosol Sci. Technol. 51, 1-11 (2017).

27. Farsalinos, K. E., Romagna, G., Tsiapras, D., Kyrzopoulos, S. \& Voudris, V. Evaluation of Electronic Cigarette Use (Vaping) Topography and Estimation of Liquid Consumption: Implications for Research Protocol Standards Definition and for Public Health Authorities. Regulation. Int. J. Environ. Res. Public Heal. Int. J. Environ. Res. Public Heal. 103390, 2500-2514 (2013).

28. Bates, C. D. \& Farsalinos, K. E. E-cigarettes need to be tested for safety under realistic conditions. Addiction 110, 1688-1689 (2015).

29. Dawkins, L. E., Kimber, C. F., Doig, M., Feyerabend, C. \& Corcoran, O. Self-titration by experienced e-cigarette users: blood nicotine delivery and subjective effects. Psychopharmacology. 233, 2933-2941 (2016).

30. Kośmider, L., Kimber, C. F., Kurek, J., Corcoran, O. \& Dawkins, L. E. Compensatory Puffing With Lower Nicotine Concentration E-liquids Increases Carbonyl Exposure in E-cigarette Aerosols. Nicotine Tob. Res., https://doi.org/10.1093/ntr/ntx162 (2017).

31. Dawkins, L. et al. 'Real-world' compensatory behaviour with low nicotine concentration e-liquid: subjective effects and nicotine, acrolein and formaldehyde exposure. Addiction 113, 1874-1882 (2018)

32. Goniewicz, M. L. et al. Levels of selected carcinogens and toxicants in vapour from electronic cigarettes. Tob. Control 23, 133-139 (2014).

33. US EPA, Risk Information System Division, I. Formaldehyde (CASRN 50-00-0)|IRIS|US EPA., https://cfpub.epa.gov/ncea/iris/iris_ documents/documents/subst/0419_summary.pdf.

34. Monticello, T. M. et al. Correlation of regional and nonlinear formaldehyde-induced nasal cancer with proliferating populations of cells. Cancer Res. 56, 1012-1022 (1996).

35. Swenberg, J. A. et al. Formaldehyde Carcinogenicity Research. Toxicol. Pathol. 41, 181-189 (2013).

36. Talih, S. et al. Characteristics and toxicant emissions of JUUL electronic cigarettes. Tob. Control, https://doi.org/10.1136/ tobaccocontrol-2018-054616 (2019)

37. Pankow, J. F., Strongin, R. M. \& Peyton, D. H. Formaldehyde from e-cigarettes-it's not as simple as some suggest. Addiction 110, $1687-1688$ (2015).

38. Sleiman, M. et al. Emissions from Electronic Cigarettes: Key Parameters Affecting the Release of Harmful Chemicals. Environ. Sci. Technol. 50, 9644-9651 (2016).

39. Farsalinos, K. E. \& Voudris, V. Do flavouring compounds contribute to aldehyde emissions in e-cigarettes? Food Chem. Toxicol. 115, 212-217 (2018).

40. Etter, J.-F., Zäther, E. \& Svensson, S. Analysis of refill liquids for electronic cigarettes. Addiction 108, 1671-1679 (2013).

41. Goniewicz, M. L. et al. Nicotine levels in electronic cigarette refill solutions: A comparative analysis of products from the US, Korea, and Poland. Int. J. Drug Policy 26, 583-588 (2015).

42. Trehy, M. L. et al. Analysis of electronic cigarette cartridges, refill solutions, and smoke for nicotine and nicotine related impurities. J. Liq. Chromatogr. Relat. Technol. 34, 1442-1458 (2011).

43. Peace, M. R. et al. Concentration of Nicotine and Glycols in 27 Electronic Cigarette Formulations. J. Anal. Toxicol. 40, 403-407 (2016).

44. Davis, B., Dang, M., Kim, J. \& Talbot, P. Nicotine Concentrations in Electronic Cigarette Refill and Do-It-Yourself Fluids. Nicotine Tob. Res. 17, 134-141 (2015).

45. Goniewicz, M. L., Hajek, P. \& McRobbie, H. Nicotine content of electronic cigarettes, its release in vapour and its consistency across batches: regulatory implications. Addiction 109, 500-507 (2014).

46. Etter, J.-F. \& Bugey, A. E-cigarette liquids: Constancy of content across batches and accuracy of labeling. Addict. Behav. 73, 137-143 (2017) 
47. Cox, S. et al. E-cigarette puffing patterns associated with high and low nicotine e-liquid strength: Effects on toxicant and carcinogen exposure. BMC Public Health 16, https://doi.org/10.1186/s12889-016-3653-1 (2016)

48. US EPA. Basic Information about the Integrated Risk Information System, https://www.epa.gov/iris/basic-information-aboutintegrated-risk-information-system.

49. Fowles, J. \& Dybing, E. Application of toxicological risk assessment principles to the chemical constituents of cigarette smoke. Tob. Control 12, 424-430 (2003).

\section{Acknowledgements}

This study was supported by grant C50878/A21130 from Cancer Research UK. LK is supported by the National Institute on Drug Abuse of the National Institutes of Health under Award Number U54DA036105, and the Center for Tobacco Products of the U.S. Food and Drug Administration. The content is solely the responsibility of the authors and does not necessarily represent the views of the NIH or the FDA.

\section{Author contributions}

L.D. and L.K. conceptualized the project. L.K., M.Z. and J.K. conducted the chemical analysis. L.K. and L.D. handled the interpretation of the data. L.K. handled the first drafting of the manuscript with subsequent key input from L.D., C.K. and S.C.. L.K., S.C., M.Z., J.K., M.L.G., H.M.c.R., C.K. and L.D. contributed substantially to the writing of the manuscript.

\section{Competing interests}

L.K. worked in the Institute of Occupational Medicine and Environmental Health, which is a public body, which, besides research works, offers expertise and conduct analyses on behalf of the Polish government and the industry. L.K. worked as an expert for the Polish National Committee for Standardization and for the European Committee for standardization of requirements and test methods for e-liquids and emissions. C.K. and declare no competing interests. J.K. and M.Z. worked in the Institute of Occupational Medicine and Environmental Health, which is a public body, which, besides research, offers expertise and conduct analyses on behalf of the Polish government and the industry. L.D. has previously (2010-2013) conducted research for several independent electronic cigarette companies. These companies had no input into the design, conduct or write up of the projects. She has also acted as a consultant for the pharmaceutical industry $(2015,2017)$ and as an expert witness in a patent infringement case (2015). HM has received honoraria for speaking at smoking cessation meetings and attending advisory board meetings that have been organized by Pfizer and Johnson \& Johnson. M.L.G. received a research grant from Pfizer and served as a member of scientific advisory board to Johnson\&Johnson, manufacturers of smoking cessation medications. We further confirm that this work has not been published and is not considered in any other journals for publication. Data sharing: Additional unpublished data and information are available upon request.

\section{Additional information}

Supplementary information is available for this paper at https://doi.org/10.1038/s41598-020-63292-1.

Correspondence and requests for materials should be addressed to L.K.

Reprints and permissions information is available at www.nature.com/reprints.

Publisher's note Springer Nature remains neutral with regard to jurisdictional claims in published maps and institutional affiliations.

(c) (i) Open Access This article is licensed under a Creative Commons Attribution 4.0 International

License, which permits use, sharing, adaptation, distribution and reproduction in any medium or format, as long as you give appropriate credit to the original author(s) and the source, provide a link to the Creative Commons license, and indicate if changes were made. The images or other third party material in this article are included in the article's Creative Commons license, unless indicated otherwise in a credit line to the material. If material is not included in the article's Creative Commons license and your intended use is not permitted by statutory regulation or exceeds the permitted use, you will need to obtain permission directly from the copyright holder. To view a copy of this license, visit http://creativecommons.org/licenses/by/4.0/.

(c) The Author(s) 2020 